Full length article

\title{
Surface modification of a polyethersulfone microfiltration membrane with graphene oxide for reactive dyes removal
}

\author{
Natália Cândido Homem ${ }^{\mathrm{a}, \mathrm{b}, *}$, Natália de Camargo Lima Beluci ${ }^{\mathrm{a}}$, Sara Amorim ${ }^{\mathrm{c}, \mathrm{d}, \mathrm{e}}$, Rui Reis ${ }^{\mathrm{c}, \mathrm{d}, \mathrm{e}}$, \\ Angélica Marquetotti Salcedo Vieira ${ }^{\mathrm{f}}$, Marcelo Fernandes Vieira ${ }^{\mathrm{a}}$, Rosângela Bergamasco ${ }^{\mathrm{a}}$, \\ Maria Teresa Pessoa Amorim ${ }^{\mathrm{b}}$ \\ ${ }^{a}$ Department of Chemical Engineering, State University of Maringá, 5790 Colombo Avenue, 87020-900 Maringá, Brazil \\ ${ }^{\mathrm{b}}$ Department of Textile Engineering, University of Minho, Azurém Campus, University Street, 4800-058 Guimarães, Portugal \\ c $3 B$ 's Research Group - Biomaterials, Biodegradables and Biomimetics, University of Minho, Headquarters of the European Institute of Excellence on Tissue Engineering and \\ Regenerative Medicine, AvePark, 4805-017 Barco, Guimarães, Portugal \\ d ICVS/3B's - PT Government Associate Laboratory, Braga, Guimarães, Portugal \\ ${ }^{\mathrm{e}}$ The Discoveries Centre for Regenerative and Precision Medicine, Headquarters at University of Minho, Avepark, 4805-017 Barco, Guimarães, Portugal \\ ${ }^{\mathrm{f}}$ Department of Food Engineering, State University of Maringá, 5790 Colombo Avenue, 87020-900 Maringá, Brazil
}

\section{A R T I C L E I N F O}

\section{Keywords:}

Electrostatic interaction

Reactive dyes

Graphene oxide

Membrane modification

Polyethilenimine

\begin{abstract}
A B S T R A C T
Polyethersulfone microfiltration membranes (mPES) were modified with polyethilenimine (PEI) and graphene oxide (GO) by layer-by-layer self-assembly method via electrostatic interaction using a pressurized filtration system. The high positively charge of PEI allowed it to be easily assembled on the polyethersulfone substrate, and also to receive the negative layer of GO. Several techniques were applied to characterize the modified membranes (i.e. ATR-FTIR, SEM, water angle contact and zeta potential), and proved that the modification was successfully achieved. The effect of PEI and GO concentrations in the modification was investigated, and the best performance of all membranes was achieved with a Blue Corazol (BC) dye rejection of $97.8 \%$ and a pure water permeability of $99.4 \mathrm{~L} \mathrm{~m}^{-2} \mathrm{~h}^{-1} \mathrm{bar}^{-1}$. The membrane also presented a flux recovery ratio of $>80 \%$ after being hydraulically cleaned for $30 \mathrm{~min}$. Moreover, the membrane performance was evaluated in terms of rejection of BC dye in a real dye bath wastewater, and an excellent performance with a maximum rejection rate of $96 \%$ was observed. Therefore, the proposed study may provide an efficient alternative to feasible the use of microfiltration membranes, by modifying them, in order to improve its surface characteristics and its filtration capacity, aiming to apply it in the removal of dyes of textile industries wastewater.
\end{abstract}

\section{Introduction}

In the last decades, the extensive generation of wastewater containing hazardous organic compounds, e.g. dyes, which are highly toxic, has been considered an important issue worldwide. It is estimated that about $20 \%$ of the dyes produced and used in the textile industry are discharged on the environment, as effluents, without adequate treatment, during their synthesis or dyeing process $[1,2]$. The presence of dyes in water bodies results in severe environmental problems, once that affects the light transmission and prejudices the biological processes, being toxic to the living organisms. Also, the direct contact with dyes can be toxic to human beings, and studies suggest that the consequences can range from skin diseases to cancer, among other problems [3]. Among the dyes, the reactive dyes are the most commonly used in textile industries, due to properties as bright colors and ease application. Considering that most of the reactive dyes are complex aromatic structures, recalcitrant and resistant to degradation, even when exposed to conventional and advanced treatment processes, the treatment of effluents contaminated by them is a challenge [4]. Thus, both scientific community, industries and government agencies worldwide have directed efforts on the investigation and development of efficient methods for the treatment of wastewater of textile industries [5].

Several methods have been investigated in order to remove dyes from effluents, as for example the adsorption, coagulation/flocculation and chemical or biologic degradation. Authors pointed that each one of these methods presents specific advantages and disadvantages. For instance, the adsorption process usually proves to be highly efficient,

\footnotetext{
* Corresponding author at: Department of Chemical Engineering, State University of Maringá, 5790 Colombo Avenue, $87020-900$ Maringá, Brazil.

E-mail addresses: natalia.homem@outlook.com, pg52993@uem.br (N.C. Homem).
} 
being considered as a flexible process. The coagulation/flocculation are also presented as efficient processes [6]. However, the high production of secondary products in both of these processes avoids them from being applied on an industrial scale, considering the need to carry out a subsequent treatment of the toxic sludge, which would make the process expensive [7,8]. Another technique that is been widely used in water treatment are the membrane separation processes (MSP) [5,9-11].

Although the number of MSP applications continues to increase, these processes suffer from one main disadvantage: the decrease of flux during filtration triggered by membrane fouling,

That is caused by undesirable and complex physical and chemical interactions (e.g. adsorption, adhesion, concentration polarization etc.) between the various fouling constituents in the feed and between these constituents and the membrane surface during the filtration process [12-14]. This interactions can lead to an increase in energy consumption and negatively impacts the process by rising operation cost, deteriorating permeate productivity and reducing the membrane service time [15]. The negative effect of the fouling could be diminished by membrane cleaning with chemicals. However, this might result in the degradation of the membrane material, and could affect the lifetime of the membrane [16]. In order to make membranes more resistant to problems related to fouling and to obtain improvements with respect to dye removal, some studies point out that one promising solution is the surface modification of membranes, aiming to transform them in fouling-free membranes, using nanomaterials which possess unique properties [17].

Due to its transport properties, allied with its flexibility and the one atomic thickness two-dimensional structure, recently, graphene oxide nanosheets (GO) are being applied as a potential material in the surface modification of membranes. As GO nanosheets are negatively charged, a positively charged polyelectrolyte as polyethylenimine (PEI) can be easily electrostatic bonded using several techniques, and the membrane can be modified in order to either facilitate the rejection of cations or anions [18]. Among the techniques used to deposit GO and PEI in the surface of the membranes, the layer-by-layer self-assembly technique is receiving more attention due to its simplicity. Nan et al. fabricated a positively charged membrane by assembling graphene oxide and polyethylenimine via layer-by-layer on an ultrafiltration support, and the membranes presented outstanding performance on removal of $\mathrm{Mg}^{2+}$ and $\mathrm{Na}^{+}$[19]. An ultrathin graphene oxide framework layer was also successfully deposited on a modified Torlon hollow fiber support via the layer-by-layer approach by Zhang et al. [20], and the composite membranes reached rejection values higher than $95 \%$ towards $\mathrm{Pb}^{2+}$, $\mathrm{Ni}^{2+}$, and $\mathrm{Zn}^{2+}$ with a water permeability of $4.7 \mathrm{~L} \mathrm{~m}^{-2} \mathrm{~h}^{-1} \mathrm{bar}^{-1}$. Composite hollow fiber nanofiltration membranes were prepared through layer-by-layer deposition of oppositely charged polyelectrolytes (sodium carboxymethyl cellulose (CMCNa) and polyethylenimine (PEI)) on a polypropylene hollow fiber substrate, with glutaraldehyde as crosslinker. The membrane presented pure water permeability of $14.2 \mathrm{~L} \mathrm{~m}^{-2} \mathrm{~h}^{-1} \mathrm{bar}^{-1}, \mathrm{MgCl}^{2}$ rejection of $93.2 \%$ and $\mathrm{NaCl}$ rejection of $36.2 \%$. Besides that, the membrane could also effectively remove organic dyes from aqueous solution, showing retentions of $99.8 \%, 99.6 \%$ and $99.4 \%$ to Brilliant green, Victoria blue B and Congo red, respectively [21]. Therefore, the above studies shows that the layer-by-layer deposition of oppositely charged polyelectrolytes is a promising technique and GO and PEI are modifying agents of great interest nowadays, improving the performance of the membranes in order to remove several types of contaminants and also adding antifouling properties to them [18,22-27].

In this study, the goal was to explore the surface modification of polyethersulfone microfiltration (MF) membranes (MPES), by using the layer-by-layer self-assembly method (LBL). We propose an electrostatically deposition of the layers using polyethylenimine (PEI) and graphene oxide (GO) as polycation and polyanion respectively. Next, we evaluate the performance of the produced membranes on the removal of the Blue Corazol reactive dye in aqueous solutions and in a real dye bath wastewater, as well as fouling.

\section{Experimental}

\subsection{Materials}

Graphene oxide nanosheets (GO) were prepared from graphite powder (Sigma Aldrich, $<20 \mu \mathrm{m})$. Potassium peroxodisulfate $\left(\mathrm{K}_{2} \mathrm{~S}_{2} \mathrm{O}_{8}\right.$, $\geq 99.5 \%$, Sigma-Aldrich), phosphorous pentoxide $\left(\mathrm{P}_{2} \mathrm{O}_{5}, \geq 99.5 \%\right.$, Sigma-Aldrich), potassium permanganate $\left(\mathrm{KMnO}_{4}, \geq 99.0 \%\right.$, SigmaAldrich), sulfuric acid $\left(\mathrm{H}_{2} \mathrm{SO}_{4}, \geq 98 \%\right.$, Sigma-Aldrich), hydrochloric acid ( $\mathrm{HCl} 37 \%$, Merck) and hydrogen peroxide $\left(\mathrm{H}_{2} \mathrm{O}_{2}, 30 \mathrm{wt} \%\right.$ in $\mathrm{H}_{2} \mathrm{O}$, Sigma Aldrich) were used in the synthesis of GO. Polyethylenimine (PEI, branched, M.W. 70,000, 30\% $w / v$ aq. soln.) was purchased from Alfa Aesar. The commercial PES microfiltration membranes $(47 \mathrm{~mm}$ of diameter, average pore size of $0.2 \mu \mathrm{m}$ and thickness of $165 \mu \mathrm{m}$ ) used as the support for the PEI and GO layers were purchased from Hexis Científica. For the filtration tests, the textile dye Blue Corazol RD (BC, Colourtex Industries Limited), which is a synthetic composite dye (composed by Reactive Black 5 and Reactive Blue 220) was used. Also, to simulate the filtration of a real dye bath wastewater, a pure cotton fabric $(5 \mathrm{~g})$ was dyed with BC. Acetic acid $\left(\mathrm{CH}_{3} \mathrm{CO}_{2} \mathrm{H}, \geq 99.5 \%\right.$, SigmaAldrich), sodium chloride ( $\mathrm{NaCl}, \geq 99.5 \%$, JMS LTDA), sodium carbonate $\left(\mathrm{Na}_{2} \mathrm{CO}_{3}, \geq 99.5 \%\right.$, Riedel-de-Haën) and the aftertreatment agent to wash off hydrolyzed reactive dyes Tanaterge RE (Tanatex Chemicals) were used in this dyeing process. All reagents were used as received.

\subsection{Preparation of graphene oxide nanosheets}

GO nanosheets were prepared using the modified Hummer's method adapted by Yamaguchi (2016), with some modifications. Specifically, $5 \mathrm{~g}$ of graphite powder, $2.5 \mathrm{~g}$ of $\mathrm{K}_{2} \mathrm{~S}_{2} \mathrm{O}_{8}, 2.5 \mathrm{~g}$ of $\mathrm{P}_{2} \mathrm{O}_{5}$, and $18 \mathrm{~mL}$ of $\mathrm{H}_{2} \mathrm{SO}_{4}$ were added in a round bottom flask. This mixture was kept in a reflux and constant stirring system by $80^{\circ} \mathrm{C}$, for $5 \mathrm{~h}$. After this period, the heat was turned off and the mixture was diluted with $1 \mathrm{~L}$ of deionized water. The solid obtained (pre-oxidized graphite) was filtered, rinsed with deionized water to remove the excess of acid, and dried in an oven for $12 \mathrm{~h}$ in a constant temperature of $60^{\circ} \mathrm{C}$. Subsequently, $1 \mathrm{~g}$ of the pre-oxidized graphite was diluted in $23 \mathrm{~mL}$ of $\mathrm{H}_{2} \mathrm{SO}_{4}$, under stirring in ice bath. To this mixture, $3 \mathrm{~g}$ of $\mathrm{KMnO}_{4}$ were added slowly, the mixture was kept for 5 min still under stirring, and then the ice bath was removed. The temperature was adjusted to $35^{\circ} \mathrm{C}$ and the mixture was left for reaction for $2 \mathrm{~h}$. Next, $46 \mathrm{~mL}$ of water were slowly added, keeping the temperature of the mixture under $50{ }^{\circ} \mathrm{C}$. The mixture was kept under stirring for more $2 \mathrm{~h}$ and then $140 \mathrm{~mL}$ of deionized water and $2,5 \mathrm{~mL}$ of $\mathrm{H}_{2} \mathrm{O}_{2}$ were added to end the reaction. A purification step was performed by washing the mixture with $250 \mathrm{~mL}$ of $\mathrm{HCl}$. To separate the graphite oxide obtained, the mixture was centrifuged, washed with deionized water and dried in an oven at $60^{\circ} \mathrm{C}$ for $12 \mathrm{~h}$. Finally, the graphene oxide nanosheets were obtained by exfoliation in a bath sonication for $3 \mathrm{~h}$, followed by a centrifugation at $5000 \mathrm{rpm}$ for $30 \mathrm{~min}$. The supernatant resultant was separated and used for the modification of the membranes.

\subsection{Surface modification of PES microfiltration membranes}

The pressure-assisted filtration method was used to assembly the layers on the membranes, which were modified and tested in a pressurized magnetic-stirred dead-end filtration system (HP4750 Sterlitech $^{\mathrm{TM}}$ ), presented at Fig. 1.

The membranes were placed in the system and then, three main modification steps were performed: first, to ensure a positively charged membrane surface and benefit the assembly of GO, a polyethylenimine (PEI) layer was placed on the surface of the membrane, followed by a GO layer and another layer of PEI. The layers were formed by 


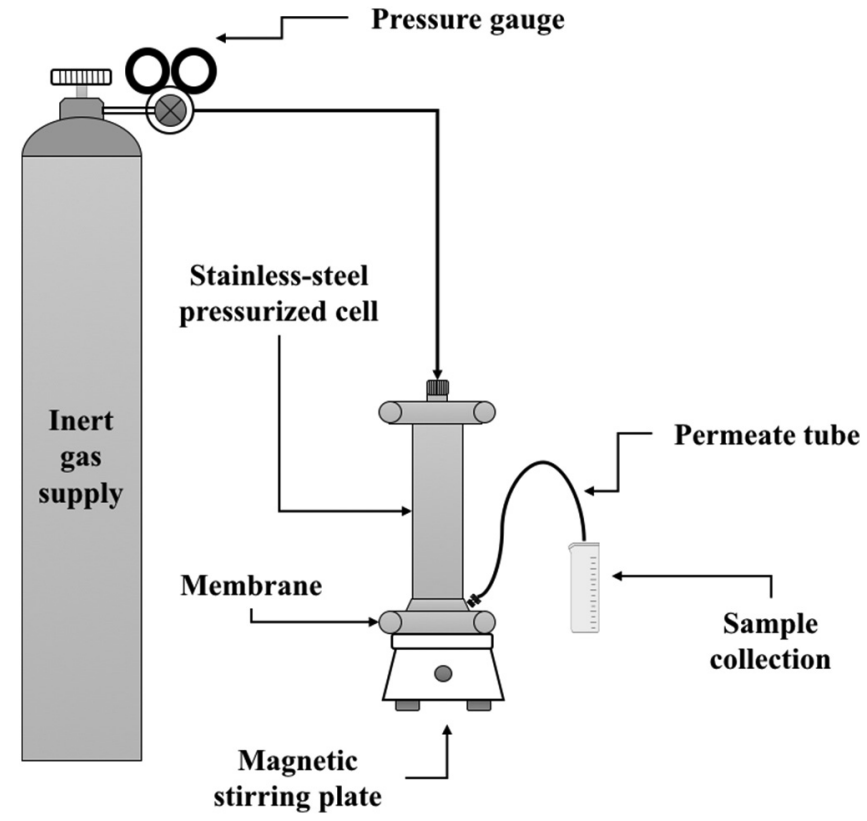

Fig. 1. Schematic diagram of the pressurized system.

permeating the PEI and GO solutions (with a fixed volume of $30 \mathrm{~mL}$ ) through the membrane, and the $\mathrm{pH}$ of these solutions was set according to an analysis of zeta potential of the GO solutions.

To evaluate the optimal conditions for the modification, the concentrations of PEI and GO were evaluated, and the best concentration for each layer was choose by evaluating some important parameters in the filtration tests, i.e. pure water permeability, rejection of dye and flux recovery ratio. As presented in Table 1, the obtained membranes were labeled as $\mathrm{mPES} / \mathrm{PEI}_{\mathrm{a}}+\mathrm{GO}_{\mathrm{b}}+\mathrm{PEI}_{\mathrm{c}}$, in which $\mathrm{a}$, b and c corresponds to the PEI and GO concentrations (in $\mathrm{g} / \mathrm{L}$ ).

\subsection{Characterization}

A UV-VIS scanning spectrophotometer (UV-1800, Shimadzu) with a $1 \mathrm{~cm}$ cuvette was used to measure the absorbance of GO, BC and dye bath solutions. The measurements were made at a wavelength range between 200 and $800 \mathrm{~nm}$.

To determine the charge properties of the GO solutions, a zeta potential analysis was performed in a Nano Zeta Potential \& Submicron Particle Size Analyzer equipment (Beckman Coulter). The measures of zeta-potential were performed at the $\mathrm{pH}$ values of $2,4,6,8,10$ and 12 at a GO concentration of $0.1 \mathrm{~g} / \mathrm{L}$, without the addition of any further

Table 1

PEI and GO concentrations used in the modification solutions.

\begin{tabular}{|c|c|c|c|}
\hline \multirow[t]{2}{*}{ Membranes } & \multicolumn{3}{|c|}{ Concentrations (g/L) } \\
\hline & $\begin{array}{l}\text { 1st layer - } \\
\text { PEI }\end{array}$ & $\begin{array}{l}\text { 2nd layer - } \\
\text { GO }\end{array}$ & 3rd layer - PEI \\
\hline mPES (pristine) & 0 & 0 & 0 \\
\hline $\mathrm{mPES} / \mathrm{PEI}_{0}+\mathrm{GO}_{0.025}+\mathrm{PEI}_{1.5}$ & 0 & 0.025 & 1.5 \\
\hline $\mathrm{mPES} / \mathrm{PEI}_{1.5}+\mathrm{GO}_{0.025}+\mathrm{PEI}_{1.5}$ & 1.5 & 0.025 & 1.5 \\
\hline $\mathrm{mPES} / \mathrm{PEI}_{3.0}+\mathrm{GO}_{0.025}+\mathrm{PEI}_{1.5}$ & 3.0 & 0.025 & 1.5 \\
\hline $\mathrm{mPES} / \mathrm{PEI}_{\mathrm{a}}+\mathrm{GO}_{0.05}+\mathrm{PEI}_{1.5}$ & (a) & 0.050 & 1.5 \\
\hline $\mathrm{mPES} / \mathrm{PEI}_{\mathrm{a}}+\mathrm{GO}_{\mathrm{b}}+\mathrm{PEI}_{0}$ & (a) & (b) & 0 \\
\hline $\mathrm{mPES} / \mathrm{PEI}_{\mathrm{a}}+\mathrm{GO}_{\mathrm{b}}+\mathrm{PEI}_{1.5}$ & (a) & (b) & 1.5 \\
\hline $\mathrm{mPES} / \mathrm{PEI}_{\mathrm{a}}+\mathrm{GO}_{\mathrm{b}}+\mathrm{PEI}_{3.0}$ & (a) & (b) & 3.0 \\
\hline $\mathrm{mPES} / \mathrm{PEI}_{\mathrm{a}}+\mathrm{GO}_{\mathrm{b}}+\mathrm{PEI}_{\mathrm{c}}$ & (a) & (b) & (c) \\
\hline
\end{tabular}

Note: In the Table (a), (b) and (c) are the concentrations where the membranes presented the best performance when considering the pure water permeability, flux recovery ratio and removal of dye. ionic species.

A SurPASS electrokinetic analyzer (EKA, Anton Paar, Austria) was used to determine the surface zeta potentials of the pristine and modified membranes. The samples ( $13 \mathrm{~mm}$ round) were mounted in a cylindric adjustable-gap cell, and the gap was set to $110 \pm 5 \mathrm{um}$. A $1 \mathrm{mM}$ $\mathrm{KCl}$ solution was used as electrolyte and was flowed at $400 \mathrm{mBar}$. The streaming current (Istr) was determined at different $\mathrm{pH}$ from 11 to 3 with automatic titration of $0.05 \mathrm{M} \mathrm{HCl}$. Each zeta potential was calculated and averaged over four measurements using the Attract 2.0 software.

The surface chemistry and chemical composition of the commercial and modified membranes were analyzed by attenuated total reflectance-Fourier transform infrared spectroscopy (ATR-FTIR). The equipment used was an IRAffinity-1S (Shimadzu), coupled with a HATR 10 accessory with a diamond crystal. The spectra were obtained in a wavenumber range of $400-4000 \mathrm{~cm}^{-1}$, in a velocity scan of 64 scans $\min ^{-1}$ and resolution of $4 \mathrm{~cm}^{-1}$.

The morphology of the membranes was analyzed by a Scanning Electron Microscopy (SEM) (Quanta FEI model 250). The samples were previously covered by a thin layer of gold to conduct electricity, and the micrography's were taken with a magnification of 500, 1000 and 5000, and 10,000 times. All measurements were conducted at standard highvacuum conditions.

The surface hydrophilicity/hydrophobicity of the membranes was evaluated by water contact angle (WCA) in a goniometer system (OCA 15 PLUS, DataPhysics), using the sessile-drop method. Before the characterization tests, the membranes were dried overnight at room temperature. Each one of the analysis were repeated at least 5 times in different places of the surface of the membranes, to reduce error. To the WCA measurements, a micro syringe with a stainless-steel needle dropped a $0.3 \mu \mathrm{L}$ drop of distilled water on the surface of the membrane. The images of the static angle were recorded, and the data was saved on the software of the equipment. The results of the measurements were achieved by an average between the five-analysis made.

\subsection{Separation properties of the modified membranes}

The performance of the membranes was investigated in the same pressurized and magnetically stirred system in which the modification was done. The system has a feed tank of $300 \mathrm{~mL}$ of capacity, to store the solution to be filtrated. The commercial and modified membranes, with an effective surface area of $12.56 \mathrm{~cm}^{2}$, were fixed at the center of the filtration module, supported by a porous stainless-steel disc. All the experiments were performed at room temperature and when it referred to "pure water", the feed was distilled water.

Initially, the pure water permeability (PWP, $\mathrm{L} \mathrm{m}^{-2} \mathrm{~h}^{-1} \mathrm{bar}^{-1}$ ) (i.e. the pure water flux normalized by transmembrane pressure) of the membranes was obtained by varying the pressures (1, 2 and 3 bar). For the fouling investigation (in this case, evaluated by the flux recovery ratio), the pure water fluxes of the modified and unmodified membranes $\left(\mathrm{J}_{0}\right)$ were obtained at constant pressure of 3 bar. Subsequently, the membranes were tested to determine the textile dye Blue Corazol (BC) removal, at natural $\mathrm{pH}$ (approximately 6) and concentration of $10 \mathrm{ppm}$, keeping the same pressure (3 bar). Finally, the membranes were hydraulically cleaned for $30 \mathrm{~min}$ [28], and a final step of filtration with pure water was realized, being the pure water flux of this step $\left(\mathrm{J}_{1}\right)$ also obtained.

The pure water fluxes $\left(\mathrm{J}_{0}\right.$ and $\left.\mathrm{J}_{1}\right)$ were determined through Eq. (1):

$\mathrm{J}=\frac{\mathrm{Q}}{\mathrm{APt}}$

where $Q$ is the volume of permeate (L), $A$ is the effective surface area of membrane $\left(\mathrm{m}^{2}\right), \mathrm{P}$ is the filtration pressure (bar), and $t$ is the running time (h).

The rejection rate for the dye $(R, \%)$ was determined through Eq. (2): 
$\mathrm{R}=\left(1-\frac{C_{p}}{C_{f}}\right) \times 100$

where $C_{p}$ and $\mathrm{C}_{\mathrm{f}}$ are the solute concentrations in permeate and feed, respectively [20]. The concentration of BC was analyzed using a UV-VIS scanning spectrophotometer (UV-1800, Shimadzu, Japan) at a wavelength of $602 \mathrm{~nm}$.

The flux recovery ratio (FRR, \%) was calculated by the ratio between the flux of pure water before $\left(\mathrm{J}_{0}\right)$ and after $\left(\mathrm{J}_{1}\right)$ the filtration of the dye, as showed at Eq. (3) [29]:

Flux recovery ratio $=\frac{J_{1}}{J_{0}} \times 100$

\subsection{Preparation of the real dye bath wastewater}

After exploring the best surface modification conditions for the removal of the BC dye from aqueous solutions, filtration tests with a real dye bath wastewater were also performed. Firstly, a dye bath (with a ratio between the weight of the cotton and the water volume of 1:20) was prepared. For that, a cotton fabric sample was dyed using real conditions, as specified in the manual of utilization of this dye. Initially, the sample was immersed in a $100 \mathrm{~mL} 0.5 \%$ of BC dye solution, containing $2.5 \mathrm{~g}$ of $\mathrm{NaCl}$ and $0.7 \mathrm{~g}$ of $\mathrm{Na}_{2} \mathrm{CO}_{3}$. This solution was placed in a dyeing machine and submitted to a heating ramp of $10^{\circ} \mathrm{C} / \mathrm{min}$, until the temperature of $80^{\circ} \mathrm{C}$ was achieved, and kept for $110 \mathrm{~min}$. A neutralization step was performed by immersing the already dyed sample in an acetic acid solution $(1 \mathrm{~g} / \mathrm{L})$ for $10 \mathrm{~min}$ at $40^{\circ} \mathrm{C}$. After that, the sample was washed with a solution $(0.1 \% \mathrm{v} / \mathrm{v})$ of Tanaterge RE product (aftertreatment agent used to wash off hydrolyzed reactive dyes) at $98^{\circ} \mathrm{C}$ for more $15 \mathrm{~min}$. Finally, the sample was rinsed with cold distilled water. The further filtration experiments of real wastewater were performed with the mixing of the all dye baths, at pH 6 and also in the natural $\mathrm{pH}$ of the effluent (approximately 10).

\section{Results and discussion}

\subsection{Characterization}

\subsubsection{Zeta potential of $G O$ solutions}

It is well-known that PEI is a polycation and thus can increase the surface charge of membranes [30-32]. Also, if we consider that a strong interaction is required to achieve stability of the electrostatically assembled layers on the membrane, it is important that the $\mathrm{pH}$ of the GO solutions used in the modification of the membranes are according its charges properties [18]. In this case, as more negative the potential zeta of the GO solution is, more the PEI and GO layers will be attracting themselves electrostatically, once GO act as a polyanion. The zeta potentials of the $\mathrm{GO}$ solutions at different $\mathrm{pH}$ values are presented at Fig. 2.

As can be seen in Fig. 2, GO solutions were able to remain negatively charged over a pH range between 2 until 12, being the highest negative zeta potential achieved at $\mathrm{pH} 10(-33.9 \mathrm{mV})$. Thus, to ensure a more negative behavior of GO in the further modification steps, this was the $\mathrm{pH}$ chosen to be used for the GO solutions.

On the other hand, to avoid an additional step of $\mathrm{pH}$ adjustment, the $\mathrm{pH}$ of PEI solutions (for both first and third layers) was held at 6.5, which was the natural $\mathrm{pH}$ of the solution.

The membranes were submitted to characterization techniques aiming a better understanding of modification process and its effects, as well as to compare the performance of the membranes before and after its modification.

\subsubsection{Attenuated total reflectance-Fourier transform infrared spectroscopy (ATR-FTIR)}

ATR-FTIR spectra presented at Fig. 3 was used to better understand

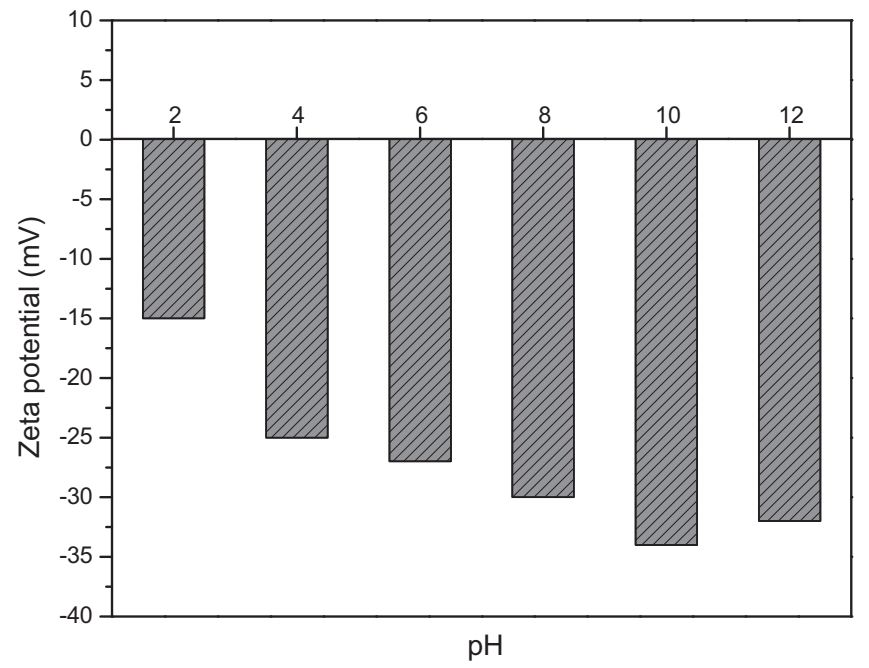

Fig. 2. Zeta potential of the GO solution at different $\mathrm{pH}$ values.

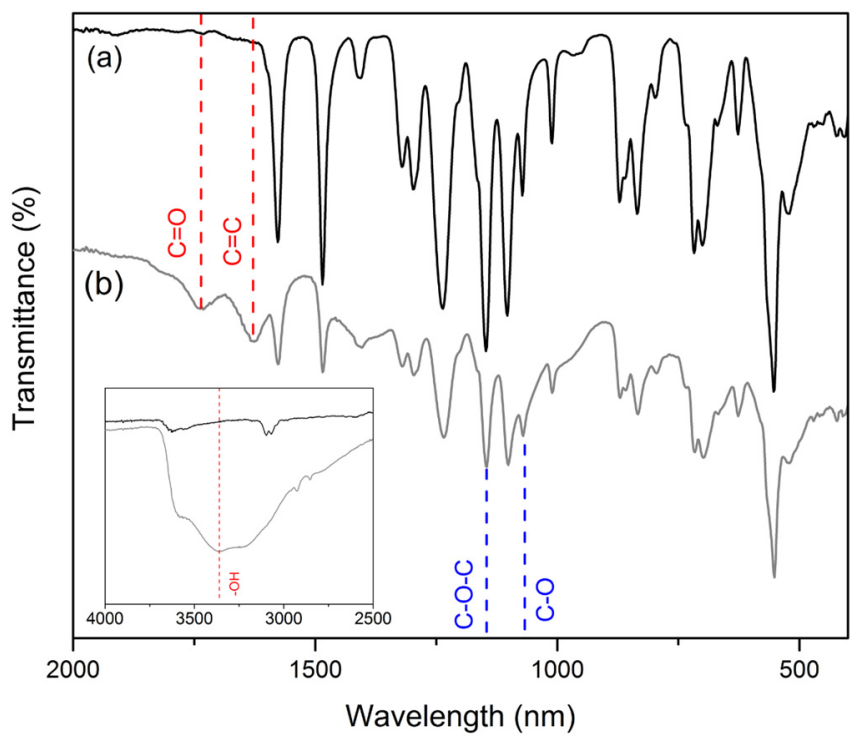

Fig. 3. ATR-FTIR spectra of the (a) mPES and the (b) mPES/PEI + GO + PEI membranes.

the modification of the membranes. In the spectra of the modified membrane (Fig. 3, (b)) the first thing that can be observed is the appearance of an additional peak in the range between 3300 and $3600 \mathrm{~cm}^{-1}$, which can be attributed both for the amine stretch of primary and secondary aliphatic amines $(-\mathrm{NH})$ as to the $-\mathrm{OH}$ stretching of hydroxyl groups. Peaks attributed to carboxyl $(\mathrm{C}=\mathrm{O}$ stretching at $1722 \mathrm{~cm}^{-1}$ ), epoxy (C-O-C stretching at $1243 \mathrm{~cm}^{-1}$ ) and alkoxy groups (C-O stretching at $1050 \mathrm{~cm}^{-1}$ ) can also be observed. Moreover, a peak in $1626 \mathrm{~cm}^{-1}$ that did not appear in the spectra of the unmodified membrane (Fig. 3 (a)) can be attributed to the $\mathrm{C}=\mathrm{C}$ vibration of aromatic group of graphene. These results are in agree with previous studies, which pointed out that the appearance of these peaks indicates the success of the GO and PEI deposition in membranes [25,29,33-35]. Other bands that can be observed at 1578,1485 , and $1240 \mathrm{~cm}^{-1}$ which can be assigned to the aromatic bands of benzene ring, $\mathrm{C}=\mathrm{C}$ bond stretch, and aromatic ether, respectively, are characteristics of PES membrane [36,37].

\subsubsection{Scanning electronic microscopy (SEM)}

Fig. 4 (a-d) shows the surface morphology of the commercial and each step of modification of the membranes. It can be observed that for 
(a)

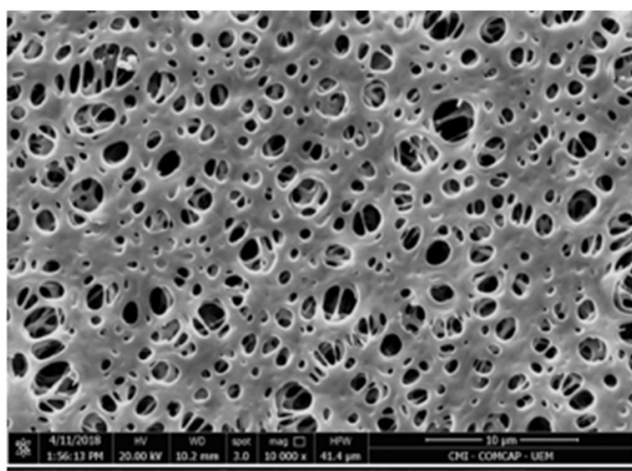

(c)

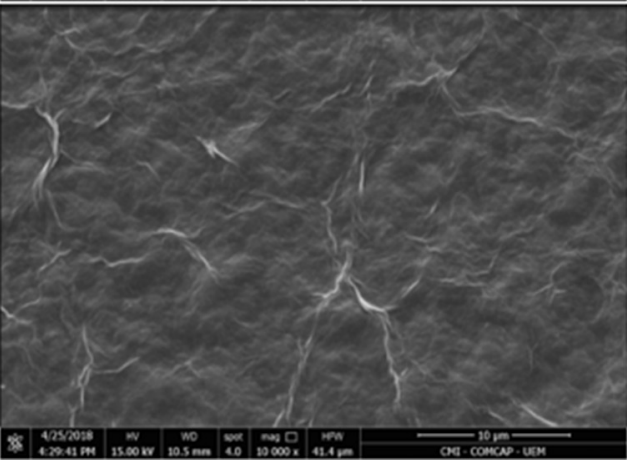

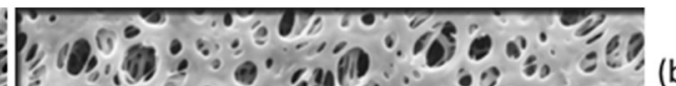

(b)
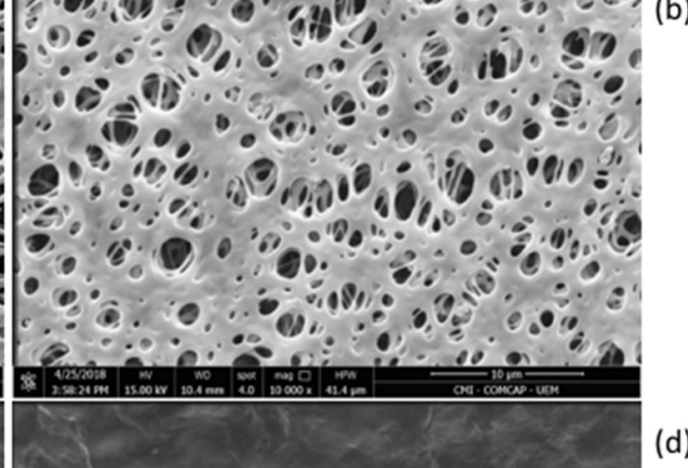

(d)

Fig. 4. SEM images of (a) mPES membrane; (b) mPES/PEI membrane; (c) mPES/PEI + GO membrane and (d) mPES/PEI + GO + PEI membrane in a 10,000 $\times$ magnification.

the unmodified membrane and after the first layer of PEI assembly (Fig. 4 (a,b)) the images presented a surface uniform with many visible pores. When the first GO layer is assembled, the surface is completely covered, and these pores becomes practically indiscernible (Fig. 4 (c)).

At the last image, it can be observed that when the last PEI layer is assembled, the surface becomes more uniform, and a decrease in the visible defects and wrinkles that appear when the GO layer was assembled is observed. These more apparent superficial defects on the surface of the membranes are mostly due to the GO nanosheets folding effect during filtration assembly, and was also observed by other authors $[19,38,39]$.

\subsubsection{Water contact angle (WCA)}

The water contact angle measurements of the commercial and modified membranes are presented in Table 2.

As can be observed, the unmodified membrane showed a higher water contact angle when compared to the modified membranes. However, the average water contact angle for the mPES/PEI + GO + PEI membrane was higher than to the one found for the mPES/ $\mathrm{PEI}+\mathrm{GO}$ membrane. This can imply that when PEI is assembled, its interaction with GO tends to increase slightly the membrane resistance. Nevertheless, the results suggest that the surface modification of the membranes enhanced the hydrophilicity of them, mainly due to the fact that the GO is abundant in functional groups (as showed previously in FTIR results), i.e. epoxide, carboxyl, and hydroxyl groups, which are responsible for hydrophilic properties. Also, previous studies presented similar behavior for the use of GO in surface modification of membranes $[22,40,41]$.

Table 2

Water contact angle for commercial and modified membranes.

\begin{tabular}{ll}
\hline Membrane & Water contact angle $\left(^{\circ}\right)$ \\
\hline mPES & $63.9 \pm 4$ \\
mPES/PEI + GO & $55.0 \pm 5$ \\
mPES/PEI + GO + PEI & $59.3 \pm 4$
\end{tabular}

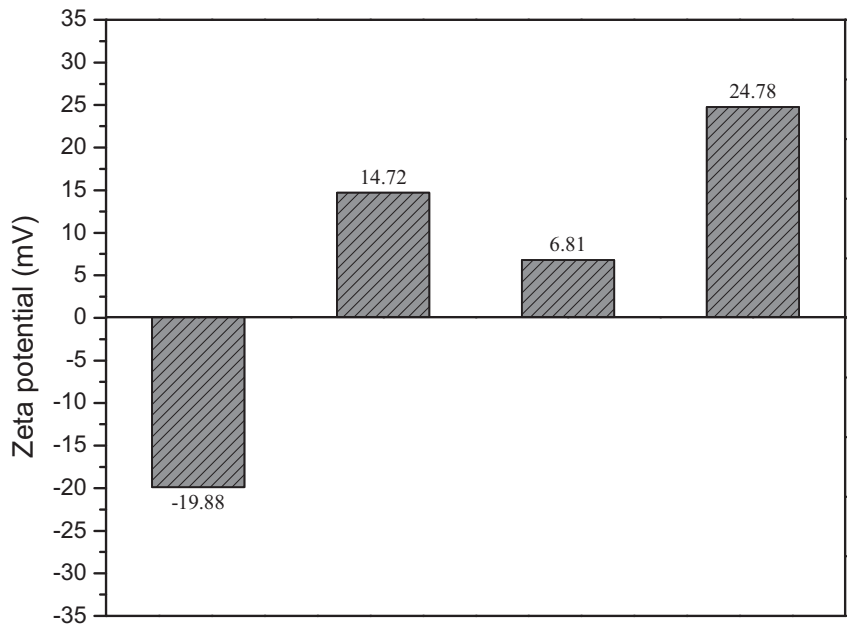

(a)

(b)

(c)

(d)

Fig. 5. Surface zeta potential of (a) mPES membrane; (b) mPES/PEI membrane; (c) $\mathrm{mPES} / \mathrm{PEI}+\mathrm{GO}$ membrane and (d) mPES/PEI + GO + PEI membrane at pH 6.

\subsubsection{The membrane zeta potentials}

The zeta potentials of the pristine and modified membranes at $\mathrm{pH} 6$ are shown in Fig. 5(a-d). It can be observed that the unmodified membrane (Fig. 5(a)) presents a negative zeta potential of $-19.88 \mathrm{mV}$, which changes to a positive zeta potential of $+14.72 \mathrm{mV}$ when the first PEI layer is assembled (Fig. 5(b)). This behavior corresponds to the expected since PEI is a polycation. On the other hand, within the GO layer assembly on the membrane (Fig. 5(c)) it is observed a decrease in the surface charge to $+6.81 \mathrm{mV}$, but the membrane surface still remains positively charged. This behavior was also observed by other authors which used GO in the surface modification of membranes $[17,19]$. By assembling an outer PEI layer on the membrane surface (Fig. 5(d)) an increase in its charge is observed, and this layer reached the highest zeta potential value for all the membranes analyzed 


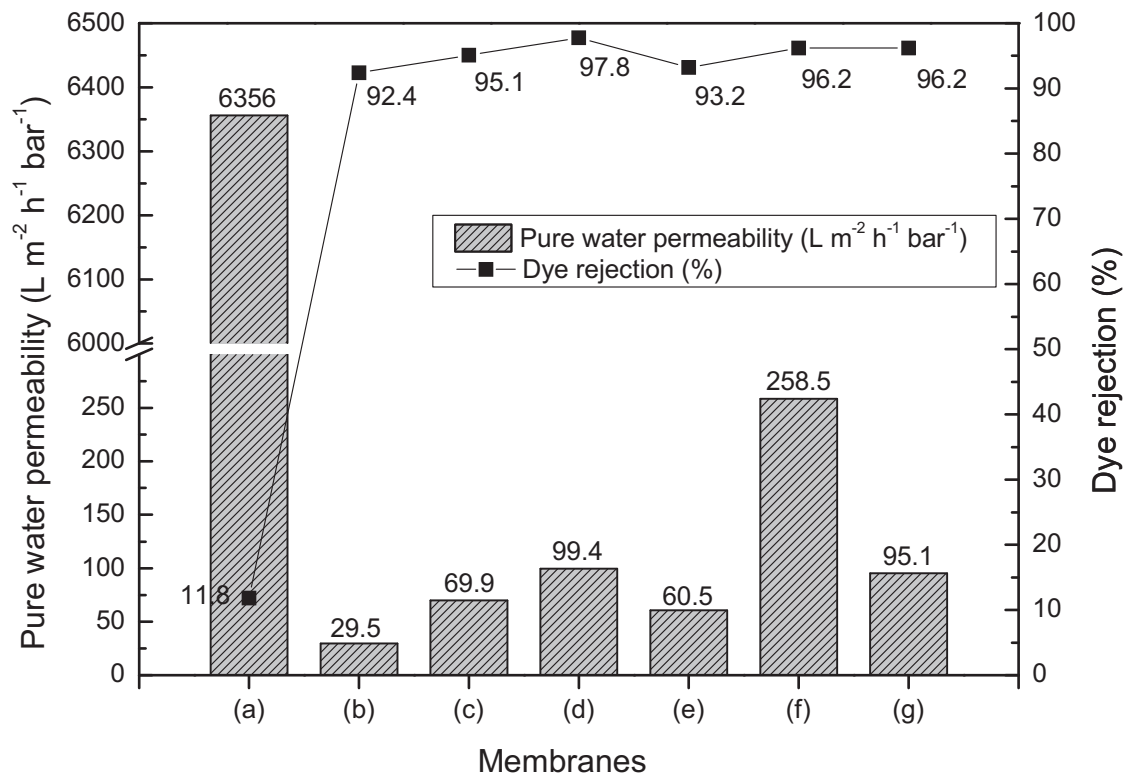

Fig. 6. PWP and dye rejection for (a) $\mathrm{mPES}$, (b) $\mathrm{mPES} / \mathrm{PEI}_{0}+\mathrm{GO}_{0.025}+\mathrm{PEI}_{1.5}$, (c) $\mathrm{mPES} / \mathrm{PEI}_{1.5}+\mathrm{GO}_{0.025}+\mathrm{PEI}_{1.5}$, (d) $\mathrm{mPES} \mathrm{PEI}_{3.0}+\mathrm{GO}_{0.025}+\mathrm{PEI}_{1.5}$, (e) $\mathrm{mPES} /$ $\mathrm{PEI}_{3.0}+\mathrm{GO}_{0.055}+\mathrm{PEI}_{1.5}$, (f) mPES/PEI ${ }_{3.0}+\mathrm{GO}_{0.025}+\mathrm{PEI}_{0}$ and (g) $\mathrm{mPES} / \mathrm{PEI}_{3.0}+\mathrm{GO}_{0.025}+\mathrm{PEI}_{3.0}$ membranes.

$(+24.78 \mathrm{mV})$. These results show that significant changes in the surface zeta potential are achieved when the layers are assembled on the membrane, demonstrating that the layer-by-layer technique is a useful and simple strategy for bonding GO nanosheets to positively charged polyelectrolytes as PEI.

\subsection{Performance of membranes}

By analyzing the separation properties of the membranes, it is possible to understand better the surface modification and optimize the process. In this study, the effect of PEI concentration on the inner and outer layers $(0,1.5$, and $3.0 \mathrm{~g} / \mathrm{L})$ and also the effect of GO concentration on the second layer $(0.025$ and $0.055 \mathrm{~g} / \mathrm{L})$ were investigated. The results concerning the membranes performance are presented in Fig. 6.

As can be observed in Fig. 6, the pure water permeability values for all the modified membranes (Fig. 6(b-g)) were pronouncedly lower when compared to that found for the unmodified membrane (Fig. 6(a)). This result suggests that the assembly of layers on the surface of the membrane formed an effective barrier, which restricts the water flux [42] as also implied by SEM images (see Section 3.1.3).

Through the analysis of the layers one by one, it can be seen that as the PEI concentration on the first layer increases from 0 to 1.5 and to 3.0 g/L (Fig. 6(b), (c) and (d), respectively), both the pure water permeability and rejection of $\mathrm{BC}$ dye increased. However, when an increase in the GO concentration occurs (second layer), the permeability decreases from 99.4 to $60.5 \mathrm{~L} \mathrm{~m}^{-2} \mathrm{~h}^{-1} \mathrm{bar}^{-1}$, while a slight decrease in dye rejection is observed (Fig. 6(d) and (e)). This can be explained by the fact that when the GO concentration is increased, a prolonged permeation time of the GO solution through the membrane in the modification step is observed. In this prolonged time, GO nanosheets can form aggregations, which are responsible for a high transport resistance of the membrane and significantly narrowing of the membrane's pore sizes. Other authors pointed out the same behavior for the use of GO nanosheets in the surface modification of membranes, even using different pore size supports $[19,20,42]$. Therefore, it can be concluded that the use of large amounts of GO in the modifications would only increase the membrane resistance, which is undesirable if the rejection rates remains similar for molecules as dyes. Thus, the concentration of $0.025 \mathrm{~g} / \mathrm{L}$ was chosen to the be the GO concentration used in further experiments.
Although an increase in PEI concentration is interesting in the first layer, the same behavior is not observed for the third layer. As can be observed in Fig. 6(f-g), an increase in PEI concentration from 0 to $3.0 \mathrm{~g} / \mathrm{L}$ led to a pronounced decrease in the pure water permeability, from 258 to $95 \mathrm{~L} \mathrm{~m}^{-2} \mathrm{~h}^{-1} \mathrm{bar}^{-1}$. Spite of the fact that the pure water permeability of the membrane without PEI in the last layer was higher than those found to the other membranes, the assembly of PEI provides a positive charge to the outer layer of the membrane surface. Also, the rejection of the dye of this membrane for the BC dye (Fig. 6(e)) presented a small decrease in comparison with the other membranes analyzed in this scenario.

However, when comparing the performance of the mPES/ $\mathrm{PEI}_{3.0}+\mathrm{GO}_{0.025}+\mathrm{PEI}_{1.5}$ (Fig. 6 (d)) with the mPES/ $\mathrm{PEI}_{3.0}+\mathrm{GO}_{0.025}+\mathrm{PEI}_{3.0}$ (Fig. $6(\mathrm{~g})$ ) membranes, it is possible to observe that the difference between the pure water permeability values is almost insignificant. Also, the dye rejection was exactly the same, not justifying the use of $3.0 \mathrm{~g} / \mathrm{L}$ of PEI I the outer layer. These results agree with those found in the flux recovery ratio analysis, presented in Fig. 7.

The flux recovery ratio is inversely proportional to the fouling, so a higher FRR suggests that the membrane possess antifouling properties [43]. As shown, all the modified membranes presented a small degree of fouling, which means that none of them recovered the initial flux completely after the dye filtration. However, the membranes which varied the PEI concentration in outer layer (Fig. 7(d and g)) presented the lesser flux reduction ratio (both membranes recovered $84.6 \%$ of the initial flux), while the pristine membrane presented the biggest reduction among all membranes (recovered only $1.36 \%$ of the initial flux).

Thus, once that the membrane labeled as mPES/ $\mathrm{PEI}_{3.0}+\mathrm{GO}_{0.025}+\mathrm{PEI}_{1.5}$ was the most resistant to problems related to fouling and presented the best performance with respect to dye removal, the PEI and GO concentrations selected for the further studies were: $3.0 \mathrm{~g} / \mathrm{L}$ for the first layer of PEI; $0.025 \mathrm{~g} / \mathrm{L}$ for the GO layer (second layer) and $1.5 \mathrm{~g} / \mathrm{L}$ for the third and last PEI layer.

\subsection{Filtration experiments of the dye bath wastewater}

A real dye bath wastewater was prepared to investigate the effectiveness of the mPES/PEI $3.0+\mathrm{GO}_{0.025}+\mathrm{PEI}_{1.5}$ membrane in a real situation. The characteristics of this real dye bath are shown in Table 3. 


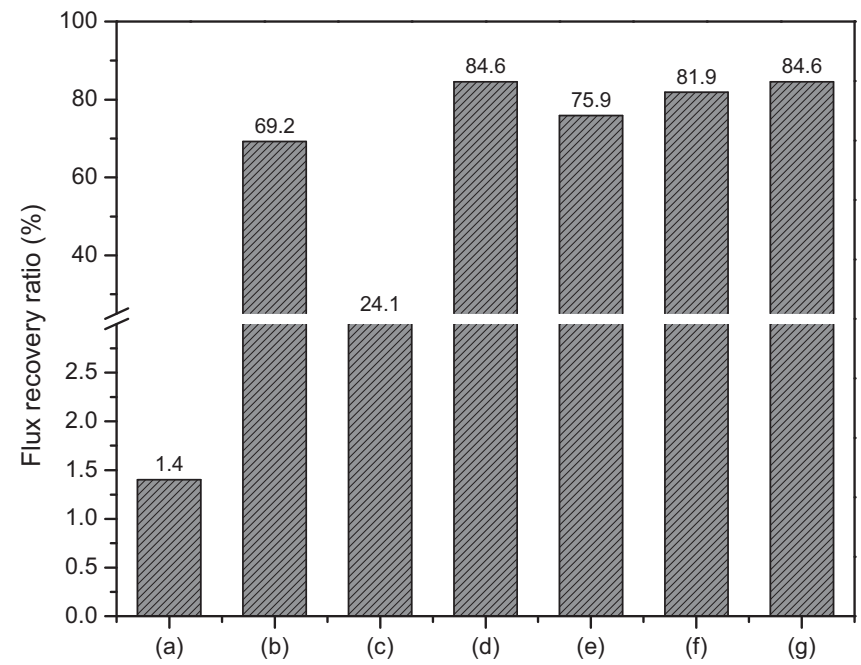

Fig. 7. FRR (\%) for (a) mPES, (b) $\mathrm{mPES} / \mathrm{PEI}_{0}+\mathrm{GO}_{0.025}+\mathrm{PEI}_{1.5}$, (c) mPES/ $\mathrm{PEI}_{1.5}+\mathrm{GO}_{0.025}+\mathrm{PEI}_{1.5}$, (d) $\mathrm{mPES} / \mathrm{PEI}_{3.0}+\mathrm{GO}_{0.025}+\mathrm{PEI}_{1.5}$, (e) $\mathrm{mPES} /$ $\mathrm{PEI}_{3.0}+\mathrm{GO}_{0.055}+\mathrm{PEI}_{1.5}$, (f) $\mathrm{mPES} / \mathrm{PEI}_{3.0}+\mathrm{GO}_{0.025}+\mathrm{PEI}_{0}$ and (g) mPES/ $\mathrm{PEI}_{3.0}+\mathrm{GO}_{0.025}+\mathrm{PEI}_{3.0}$ membranes.

Table 3

Characteristics of the real dye bath obtained in this study.

\begin{tabular}{ll}
\hline Parameters & Values \\
\hline Absorbance & 0.887 \\
Color & Dark blue \\
Concentration $(\mathrm{mg} / \mathrm{L})$ & $\cong 40$ \\
Conductivity $(\mathrm{mS} / \mathrm{cm})$ & 20.1 \\
$\mathrm{pH}$ & 10 \\
\hline
\end{tabular}

Note: the absorbance and concentration are correspondent to the textile dye BC.

Table 4

Dye rejection and permeate fluxes for the real dye bath filtration.

\begin{tabular}{llll}
\hline $\mathrm{pH}$ & $\begin{array}{l}\text { Dye concentration (mg/ } \\
\mathrm{L})\end{array}$ & $\begin{array}{l}\text { Dye rejection } \\
(\%)\end{array}$ & $\begin{array}{l}\text { Permeate flux } \\
\left(\mathrm{L} \mathrm{m}^{-2} \mathrm{~h}^{-1} \mathrm{bar}^{-1}\right)\end{array}$ \\
\hline 6 & 10 & 96.1 & 17.2 \\
6 & 40 & 91.4 & 11.4 \\
10 & 10 & 62.3 & 76.0 \\
10 & 40 & 35.4 & 33.9 \\
\hline
\end{tabular}

The filtration experiments were performed with the dye bath without varying its concentration; by diluting its concentration to $10 \mathrm{mg} / \mathrm{L}$; at $\mathrm{pH}$, and also in the natural $\mathrm{pH}$ of the effluent. The results of these experiments are presented at Table 4.

Table 4 shows that, when the $\mathrm{pH}$ of the solution was previously set to 6, the $\mathrm{mPES} / \mathrm{PEI}_{3.0}+\mathrm{GO}_{0.025}+\mathrm{PEI}_{1.5}$ membrane presented better results in terms of dye rejection, but lower permeate fluxes, when compared to those found at $\mathrm{pH} 10$. For the $\mathrm{pH} 6$, both dye rejection and the permeate fluxes increased from 91.4 to $96.1 \%$ and from 11.4 to 17.2 $\mathrm{L} \mathrm{m}^{-2} \mathrm{~h}^{-1} \mathrm{bar}^{-1}$ by decreasing the initial dye concentrations from 40 to $10 \mathrm{mg} / \mathrm{L}$, respectively. Much higher permeate fluxes were observed for pH $10\left(76.0 \mathrm{~L} \mathrm{~m}^{-2} \mathrm{~h}^{-1} \mathrm{bar}^{-1}\right.$ and $33.9 \mathrm{~L} \mathrm{~m}^{-2} \mathrm{~h}^{-1} \mathrm{bar}^{-1}$ for the initial dye concentrations of 10 and $40 \mathrm{mg} / \mathrm{L}$, respectively). On the other hand, the dye rejections for $\mathrm{pH} 10$ did not reached values higher than $62 \%$.

Considering that the real effluent prepared presented highly basic $\mathrm{pH}$, the presence of inorganic salts and aftertreatment products, the performance of the membrane can still be considered excellent. Even though more fouling agents were presented in solution, in the best scenario (pH6 and dye concentration of $10 \mathrm{mg} / \mathrm{L}$ ) the mPES/ $\mathrm{PEI}_{3.0}+\mathrm{GO}_{0.025}+\mathrm{PEI}_{1.5}$ membrane still reached $96.1 \%$ of rejection for the dye with a satisfactory permeate flux.

\subsection{Comparison with other studies}

Table 5 presents a comparison between the results found in this article and other studies presented in literature which also used membranes in order to remove dyes.

The data shows that the modification proposed in this work enabled a microfiltration PES support to achieve results quite similar of those reported by other studies applied in the removal of dyes, after a simple modification. If a correlation between dye rejection, permeate flux and flux recovery ratio is evaluated, the performance of the membranes presented in this study is even superior of those presented in Table 5.

\section{Conclusions}

In this study, a simple and innovative method (layer-by-layer selfassembly) to modify the surface and improve the efficiency of polyethersulfone microfiltration membranes, aiming the removal of reactive dyes from aqueous solutions, was investigated. By using a quick three step method, based on the electrostatic interaction of the layers, molecules of polyethylenimine and graphene oxide were assembled on the membrane surface in a pressurized system. ATR-FTIR, water contact angle, zeta potential and SEM analysis of the membranes showed that the modification was successfully achieved. The performance investigation showed that the modified membranes presented higher rejection rates for Blue Corazol reactive dye (and also to the real dye bath studied) than the neat PES membrane, reaching values above $90 \%$ of rejection. The modified membranes presented also small degree of fouling and a flux recovery ratio of $>80 \%$ after only a simple hydraulically cleaning step was accomplished.

Among the membranes tested, the one labeled as mPES/ $\mathrm{PEI}_{3.0}+\mathrm{GO}_{0.025}+\mathrm{PEI}_{1.5}$ was the most resistant to problems related to fouling and presented the best performance in terms of dye removal. When its effectiveness in a real dye bath wastewater filtration was investigated, the mPES/PEI $3.0+\mathrm{GO}_{0.025}+\mathrm{PEI}_{1.5}$ showed that the modification proposed in this study can also be applied in the effluent treatment in a real situation, having an excellent performance (a

Table 5

Dye removal performances of membranes.

\begin{tabular}{|c|c|c|c|c|c|c|c|}
\hline Membrane & Feed solution & Rejection (\%) & $\begin{array}{l}\text { Permeate flux } \\
\left(\mathrm{L} \mathrm{m}^{-2} \mathrm{~h}^{-1}\right)\end{array}$ & $\begin{array}{l}\text { Pressure } \\
\text { (bar) }\end{array}$ & FRR (\%) & $\begin{array}{l}\text { Molecular weight of } \\
\text { dye }\left(\mathrm{g} \mathrm{mol}^{-1}\right)\end{array}$ & Reference \\
\hline PPSU/ZSM -5 & Reactive Black 5 & 90.8 & 38.0 & 3 & 68.7 & 991.8 & [44] \\
\hline Hollow fiber membrane & Reactive Orange 16 & 82.8 & 43.70 & & & 617.5 & \\
\hline \multirow[t]{2}{*}{ NFM3 } & Reactive Black 5 & 96 & - & 4 & 91.9 & 991.8 & [45] \\
\hline & Reactive Red 49 & 92 & - & & & 576.5 & \\
\hline Sulfonated PES (NTR-7450) & Reactive Blue 2 & 92.1 & 64 & 20 & Not Available & 840.10 & {$[46]$} \\
\hline $\mathrm{mPES} / \mathrm{PEI}_{3.0}+\mathrm{GO}_{0.025}+\mathrm{PEI}_{1.5}$ & $\begin{array}{l}\text { Blue Corazol (Reactive Black } 5 \\
\text { and Reactive Blue 220) }\end{array}$ & 97.8 & 107.4 & 3 & 84.6 & $\begin{array}{l}991.8 \\
733.1\end{array}$ & This study \\
\hline
\end{tabular}

PPSU: polyphenylsulfone; ZSM-5: zeolite; NFM3: Chitosan-Montmorillonite hybrid membranes; PES: polyethersulfone; PEI: polyethilenimine; GO: graphene oxide. 
rejection rate of 96\%) even that inorganic salts and aftertreatment products are present.

Therefore, it can be concluded that the proposed modification can be considered as an efficient alternative to modify the surface of microfiltration PES membranes, in order to improve its surface characteristics and its filtration capacity aiming to apply it in the removal of dyes of textile industries wastewater.

\section{Acknowledgements}

This work was funded by the Fundação para a Ciência e a Tecnologia (FCT), project $n^{\circ}$ POCI-01-0145-FEDER-007136 (UID/CTM/ 00264/2013). The authors would also like to thank Coordenação de Aperfeiçoamento de Pessoal de Nível Superior (CAPES) for the financial support and for scholarships awarded, and Universidade do Minho (UMinho) for the availability of laboratories and equipment.

\section{References}

[1] S.P.D.M. Blanco, F.B. Scheufele, A.N. Módenes, F.R. Espinoza-Quiñones, P. Marin, A.D. Kroumov, C.E. Borba, Kinetic, equilibrium and thermodynamic phenomenological modeling of reactive dye adsorption onto polymeric adsorbent, Chem. Eng. J. 307 (2017) 466-475, https://doi.org/10.1016/j.cej.2016.08.104.

[2] L. Yao, L. Zhang, R. Wang, S. Chou, Z. Dong, A new integrated approach for dye removal from wastewater by polyoxometalates functionalized membranes, $\mathrm{J}$. Hazard. Mater. 301 (2016) 462-470, https://doi.org/10.1016/j.jhazmat.2015.09. 027.

[3] R.S. Hebbar, A.M. Isloor, A.K. Zulhairun, M.S. Abdullah, A.F. Ismail, Efficient treatment of hazardous reactive dye effluents through antifouling polyetherimide hollow fiber membrane embedded with functionalized halloysite nanotubes, J. Taiwan Inst. Chem. Eng. 72 (2017) 244-252, https://doi.org/10.1016/j.jtice.2017. 01.022 .

[4] K. Chinoune, K. Bentaleb, Z. Bouberka, A. Nadim, U. Maschke, Adsorption of reactive dyes from aqueous solution by dirty bentonite, Appl. Clay Sci. 123 (2016) 64-75, https://doi.org/10.1016/j.clay.2016.01.006.

[5] H.-C. Chiu, C.-H. Liu, S.-C. Chen, S.-Y. Suen, Adsorptive removal of anionic dye by inorganic-organic hybrid anion-exchange membranes, J. Membr. Sci. 337 (2009) 282-290, https://doi.org/10.1016/j.memsci.2009.04.004.

[6] N. de Camargo Lima Beluci, G.A.P. Mateus, C.S. Miyashiro, N.C. Homem, R.G. Gomes, M.R. Fagundes-Klen, R. Bergamasco, A.M.S. Vieira, Hybrid treatment of coagulation/flocculation process followed by ultrafiltration in $\mathrm{TIO}_{2}$-modified membranes to improve the removal of reactive black 5 dye, Sci. Total Environ. 664 (2019) 222-229. doi:https://doi.org/10.1016/j.scitotenv.2019.01.199.

[7] M.T. Yagub, T.K. Sen, S. Afroze, H.M. Ang, Dye and its removal from aqueous solution by adsorption: a review, Adv. Colloid Interf. Sci. 209 (2014) 172-184, https://doi.org/10.1016/j.cis.2014.04.002.

[8] C.-Z. Liang, S.-P. Sun, F.-Y. Li, Y.-K. Ong, T.-S. Chung, Treatment of highly concentrated wastewater containing multiple synthetic dyes by a combined process of coagulation/flocculation and nanofiltration, J. Membr. Sci. 469 (2014) 306-315, https://doi.org/10.1016/j.memsci.2014.06.057.

[9] S. Dai, Y. Jiang, T. Wang, L. Wu, X. Yu, J. Lin, S. Shi, Enhanced performance of polyimide hybrid membranes for benzene separation by incorporating three-dimensional silver-graphene oxide, J. Colloid Interface Sci. 478 (2016) 145-154, https://doi.org/10.1016/j.jcis.2016.06.009.

[10] Z. Karim, A.P. Mathew, M. Grahn, J. Mouzon, K. Oksman, Nanoporous membranes with cellulose nanocrystals as functional entity in chitosan: removal of dyes from water, Carbohydr. Polym. 112 (2014) 668-676, https://doi.org/10.1016/j.carbpol. 2014.06.048.

[11] L. Shao, X.Q. Cheng, Y. Liu, S. Quan, J. Ma, S.Z. Zhao, K.Y. Wang, Newly developed nanofiltration (NF) composite membranes by interfacial polymerization for safranin $\mathrm{O}$ and aniline blue removal, J. Membr. Sci. 430 (2013) 96-105, https://doi.org/10. 1016/j.memsci.2012.12.005.

[12] F. Shao, L. Dong, H. Dong, Q. Zhang, M. Zhao, L. Yu, B. Pang, Y. Chen, Graphene oxide modified polyamide reverse osmosis membranes with enhanced chlorine resistance, J. Membr. Sci. 525 (2017) 9-17, https://doi.org/10.1016/j.memsci.2016. 12.001.

[13] W. Guo, H.-H. Ngo, J. Li, A mini-review on membrane fouling, Bioresour. Technol. 122 (2012) 27-34, https://doi.org/10.1016/j.biortech.2012.04.089.

[14] J. Chen, M. Zhang, F. Li, L. Qian, H. Lin, L. Yang, X. Wu, X. Zhou, Y. He, B.-Q. Liao, Membrane fouling in a membrane bioreactor: high filtration resistance of gel layer and its underlying mechanism, Water Res. 102 (2016) 82-89, https://doi.org/10. 1016/j.watres.2016.06.028.

[15] X. Qu, X. Cai, M. Zhang, H. Lin, Z. Leihong, B.-Q. Liao, A facile method for simulating randomly rough membrane surface associated with interface behaviors, Appl. Surf. Sci. 427 (2018) 915-921, https://doi.org/10.1016/j.apsusc.2017.08.013.

[16] J. Ayyavoo, T.P.N. Nguyen, B.-M. Jun, I.-C. Kim, Y.-N. Kwon, Protection of polymeric membranes with antifouling surfacing via surface modifications, Colloids Surf. A Physicochem. Eng. Asp. 506 (2016) 190-201, https://doi.org/10.1016/j. colsurfa.2016.06.026.

[17] K. Goh, L. Setiawan, L. Wei, R. Si, A.G. Fane, R. Wang, Y. Chen, Graphene oxide as effective selective barriers on a hollow fiber membrane for water treatment process, J. Membr. Sci. 474 (2015) 244-253, https://doi.org/10.1016/j.memsci.2014.09. 057.

[18] M. Hu, B. Mi, Layer-by-layer assembly of graphene oxide membranes via electrostatic interaction, J. Membr. Sci. 469 (2014) 80-87, https://doi.org/10.1016/j. memsci.2014.06.036.

[19] Q. Nan, P. Li, B. Cao, Fabrication of positively charged nanofiltration membrane via the layer-by-layer assembly of graphene oxide and polyethylenimine for desalination, Appl. Surf. Sci. 387 (2016) 521-528, https://doi.org/10.1016/j.apsusc.2016. 06.150.

[20] Y. Zhang, S. Zhang, J. Gao, T.-S. Chung, Layer-by-layer construction of graphene oxide (GO) framework composite membranes for highly efficient heavy metal removal, J. Membr. Sci. 515 (2016) 230-237, https://doi.org/10.1016/j.memsci. 2016.05.035.

[21] Q. Chen, P. Yu, W. Huang, S. Yu, M. Liu, C. Gao, High-flux composite hollow fiber nanofiltration membranes fabricated through layer-by-layer deposition of oppositely charged crosslinked polyelectrolytes for dye removal, J. Membr. Sci. 492 (2015) 312-321, https://doi.org/10.1016/j.memsci.2015.05.068.

[22] H.M. Hegab, L. Zou, Graphene oxide-assisted membranes: fabrication and potential applications in desalination and water purification, J. Membr. Sci. 484 (2015) 95-106, https://doi.org/10.1016/j.memsci.2015.03.011.

[23] K.A. Mahmoud, B. Mansoor, A. Mansour, M. Khraisheh, Functional graphene nanosheets: the next generation membranes for water desalination, Desalination 356 (2015) 208-225, https://doi.org/10.1016/j.desal.2014.10.022.

[24] W.-S. Hung, Q.-F. An, M. De Guzman, H.-Y. Lin, S.-H. Huang, W.-R. Liu, C.-C. Hu, K.-R. Lee, J.-Y. Lai, Pressure-assisted self-assembly technique for fabricating composite membranes consisting of highly ordered selective laminate layers of amphiphilic graphene oxide, Carbon N. Y. 68 (2014) 670-677, https://doi.org/10. 1016/j.carbon.2013.11.048.

[25] N.C. Homem, N.U. Yamaguchi, M.F. Vieira, M.T.S.P. Amorim, R. Bergamasco, Surface Modification of Microfiltration Membrane with GO Nanosheets for Dyes Removal From Aqueous Solutions, (2017), https://doi.org/10.3303/CET1760044.

[26] L. Shao, J. Li, Y. Guang, Y. Zhang, H. Zhang, X. Che, Y. Wang, PVA/polyethyleneimine-functionalized graphene composites with optimized properties, Mater. Des. 99 (2016) 235-242, https://doi.org/10.1016/j.matdes.2016.03.039.

[27] N. de Camargo Lima Beluci, N.C. Homem, M.T.S.P. Amorim, R. Bergamasco, A.M.S. Vieira, Biopolymer extracted from Moringa oleifera Lam. in conjunction with graphene oxide to modify membrane surfaces, Environ. Technol. 0 (2019) 1-12, https://doi.org/10.1080/09593330.2019.1597172.

[28] T. Chidambaram, Y. Oren, M. Noel, Fouling of nanofiltration membranes by dyes during brine recovery from textile dye bath wastewater, Chem. Eng. J. 262 (2015) 156-168, https://doi.org/10.1016/j.cej.2014.09.062.

[29] Z.-B. Zhang, J.-J. Wu, Y. Su, J. Zhou, Y. Gao, H.-Y. Yu, J.-S. Gu, Layer-by-layer assembly of graphene oxide on polypropylene macroporous membranes via click chemistry to improve antibacterial and antifouling performance, Appl. Surf. Sci. 332 (2015) 300-307, https://doi.org/10.1016/j.apsusc.2015.01.193.

[30] Y. Lv, H.-C. Yang, H.-Q. Liang, L.-S. Wan, Z.-K. Xu, Nanofiltration membranes via co-deposition of polydopamine/polyethylenimine followed by cross-linking, J. Membr. Sci. 476 (2015) 50-58, https://doi.org/10.1016/j.memsci.2014.11.024.

[31] C. Feng, J. Xu, M. Li, Y. Tang, C. Gao, Studies on a novel nanofiltration membrane prepared by cross-linking of polyethyleneimine on polyacrylonitrile substrate, J. Membr. Sci. 451 (2014) 103-110, https://doi.org/10.1016/j.memsci.2013.10.003.

[32] Y. Zhou, Z. Dai, D. Zhai, C. Gao, Surface modification of polypiperazine-amide membrane by self-assembled method for dye wastewater treatment, Chin. J. Chem. Eng. 23 (2015) 912-918, https://doi.org/10.1016/j.cjche.2015.01.005.

[33] R. Liu, G. Arabale, J. Kim, K. Sun, Y. Lee, C. Ryu, C. Lee, Graphene oxide membrane for liquid phase organic molecular separation, Carbon N. Y. 77 (2014) 933-938, https://doi.org/10.1016/j.carbon.2014.06.007.

[34] S. Xia, M. Ni, T. Zhu, Y. Zhao, N. Li, Ultrathin graphene oxide nanosheet membranes with various $d$-spacing assembled using the pressure-assisted fi ltration method for removing natural organic matter, DES 371 (2015) 78-87, https://doi.org/10.1016/ j.desal.2015.06.005.

[35] T.R. Sinclair, D. Robles, B. Raza, S. van den Hengel, S.A. Rutjes, A.M. de Roda Husman, J. de Grooth, W.M. de Vos, H.D.W. Roesink, Virus reduction through microfiltration membranes modified with a cationic polymer for drinking water applications, Colloids Surf. A Physicochem. Eng. Asp. 551 (2018) 33-41, https:// doi.org/10.1016/j.colsurfa.2018.04.056.

[36] A. Abdel-Karim, T.A. Gad-Allah, A.S. El-Kalliny, S.I.A. Ahmed, E.R. Souaya, M.I. Badawy, M. Ulbricht, Fabrication of modified polyethersulfone membranes for wastewater treatment by submerged membrane bioreactor, Sep. Purif. Technol. 175 (2017) 36-46, https://doi.org/10.1016/j.seppur.2016.10.060.

[37] H. Susanto, M. Ulbricht, Characteristics, performance and stability of polyethersulfone ultrafiltration membranes prepared by phase separation method using different macromolecular additives, J. Membr. Sci. 327 (2009) 125-135, https:// doi.org/10.1016/j.memsci.2008.11.025.

[38] K. Guan, D. Zhao, M. Zhang, J. Shen, G. Zhou, G. Liu, W. Jin, 3D nanoporous crystals enabled $2 \mathrm{D}$ channels in graphene membrane with enhanced water purification performance, J. Membr. Sci. 542 (2017) 41-51, https://doi.org/10.1016/ J.MEMSCI.2017.07.055.

[39] Y. Han, Z. Xu, C. Gao, Ultrathin graphene nanofiltration membrane for water purification, Adv. Funct. Mater. 23 (2013) 3693-3700, https://doi.org/10.1002/ adfm.201202601.

[40] S. Xia, L. Yao, Y. Zhao, N. Li, Y. Zheng, Preparation of graphene oxide modified polyamide thin film composite membranes with improved hydrophilicity for natural organic matter removal, Chem. Eng. J. 280 (2015) 720-727, https://doi.org/ 10.1016/j.cej.2015.06.063. 
[41] S. Aditya Kiran, Y. Lukka Thuyavan, G. Arthanareeswaran, T. Matsuura, A.F. Ismail, Impact of graphene oxide embedded polyethersulfone membranes for the effective treatment of distillery effluent, Chem. Eng. J. 286 (2016) 528-537, https://doi.org/ 10.1016/j.cej.2015.10.091

[42] E. Igbinigun, Y. Fennell, R. Malaisamy, K.L. Jones, V. Morris, Graphene oxide functionalized polyethersulfone membrane to reduce organic fouling, J. Membr. Sci. 514 (2016) 518-526, https://doi.org/10.1016/j.memsci.2016.05.024.

[43] M. Yang, C. Zhao, S. Zhang, P. Li, D. Hou, Preparation of graphene oxide modified poly(m-phenylene isophthalamide) nanofiltration membrane with improved water flux and antifouling property, Appl. Surf. Sci. 394 (2017) 149-159, https://doi.org/ 10.1016/j.apsusc.2016.10.069.

[44] M.C. Nayak, A.M. Isloor, A. Moslehyani, N. Ismail, A.F. Ismail, Fabrication of novel
PPSU/ZSM-5 ultrafiltration hollow fiber membranes for separation of proteins and hazardous reactive dyes, J. Taiwan Inst. Chem. Eng. 82 (2018) 342-350, https:// doi.org/10.1016/j.jtice.2017.11.019.

[45] J. Zhu, M. Tian, Y. Zhang, H. Zhang, J. Liu, Fabrication of a novel "loose" nanofiltration membrane by facile blending with chitosan-montmorillonite nanosheets for dyes purification, Chem. Eng. J. 265 (2015) 184-193, https://doi.org/10.1016/ j.cej.2014.12.054.

[46] B. Van der Bruggen, B. Daems, D. Wilms, C. Vandecasteele, Mechanisms of retention and flux decline for the nanofiltration of dye baths from the textile industry, Sep. Purif. Technol. 22-23 (2001) 519-528, https://doi.org/10.1016/S1383-5866(00) 00134-9. 